\title{
密度成層下にある地衡流の組織構造*
}

\author{
辻村 真 治*1, 飯 田 雄 章*2, 長 野靖 尚*2
}

\section{Coherent Structure in Geostrophic Flow under Density Stratification}

\author{
Shinji TSUJIMURA, Oaki IIDA and Yasutaka NAGANO
}

\begin{abstract}
The coherent structure and relevant heat transport in geostrophic flows under various density stratification has been studied by using both direct numerical simulation and rapid distortion theory. It is found that in a neutrally stratified flow under system rotation, the temperature fluctuations become very close to two-dimensional and their variation is very small in the direction parallel to the axis of rotation. Under the stable stratification, the velocity and temperature fluctuations tend to oscillate with the Brunt-Väisälä frequency. Under the unstable stratification, on the other hand, vortex columns are formed in the direction parallel to the axis of rotation. However, the generation of the elongated vortex columns cannot be predicted by the rapid distortion theory. The non-linear term is required to generate these characteristic vortex columns.
\end{abstract}

Key Words: Turbulent Flow, Heat Transfer, Stratified Flow, Computational Fluid Dynamics, Geostrophic Flow, Coherent Structure, Vortex Stretching, Rapid Distortion Theory

\section{1. 緒言}

地球物理学や天体物理学上重要な流れ場では, 浮力と コリオリカといった 2 つの体積力が重畳して影響する ことがよくある。流れ場は，浮力の条件により一般に不 安定成層と安定成層に分類できる。このうち，2平板 間において，不安定成層による対流が系の回転により 受ける影響については，比較的多くの実験的研究がな されている。これらの研究により，回転系では対流が抑 制されるため，いわゆるレイリー・ベナ一ル対流は生じ ず，回転軸を渦軸とする細長い渦柱により熱輸送が行わ れることが明らかにされた (1)(2)(3).このような渦柱は， 地表近くの大気で観测されるダストデビルや，海洋で のサーマルプルームに関係している(4)(5). また，この不 安定成層下の回転乱流に関する研究は, 数値シミュレ一 ションでも行われている(6)(7)(8).これらの研究はすべ て固体壁を境界条件とする流れ場に限定されており，よ り基本的な一様乱流についての研究は行われていない. また，安定成層下にある回転系流れについての研究は，

\footnotetext{
* 原稿受付 1998 年 3 月 16 日.

*1 学生員, 名古屋工業大学大学院 (业 466-8555 名古屋市昭和区 御器所町).

*2 正員, 各古屋工業大学.
}

主に鉛直軸に沿って静水力学平衡を仮定し, 内部重力波 を無視した方程式系に基づいて行われている(9)(10)(11). 著者らの知る限り，内部重力波を伴う回転効果について の数值的，理論的な研究はまだ行われていない.

本研究では, 密度成層下にある回転流に生じる大規 模構造と熱輸送特性について検討するため，一様等方 性乱れを初期值とした直接数值シミュレーション (DNS) およびラピッドディストーション理論 (RDT) による解 析を行った.そして, 中立, 安定および不安定密度成層 下にある回軽流の熱輸送機構を，乱流構造的見地から 検討する。

\section{2. 記 号}

$$
\begin{aligned}
B o & : \text { 浮力パラメータ }=\varepsilon /(\sqrt{k} g \beta \Delta T) \\
E_{33}(\kappa) & : \overline{u_{3}^{2}} \text { の } 3 \text { 次元エネルギースペクトル } \\
E_{\omega_{3}}(\kappa) & : \overline{\omega_{3}^{2}} \text { の3 次元エネルギースペクトル } \\
E k & : \text { エクマン数 }=\nu \varepsilon^{2} /\left(2 \Omega k^{3}\right) \\
f & : \operatorname{RDT} \text { による流れ場の角振動数 } \\
k & : \text { 乱流エネルギー }=\overline{u_{i} u_{i}} / 2 \\
N & : \text { ブラント・バイサラ振動数 }=\sqrt{g \beta S_{\theta}} \\
N_{g} & : \text { 格子点数 } \\
P r & : \text { プラントル数 }=\nu / \alpha
\end{aligned}
$$




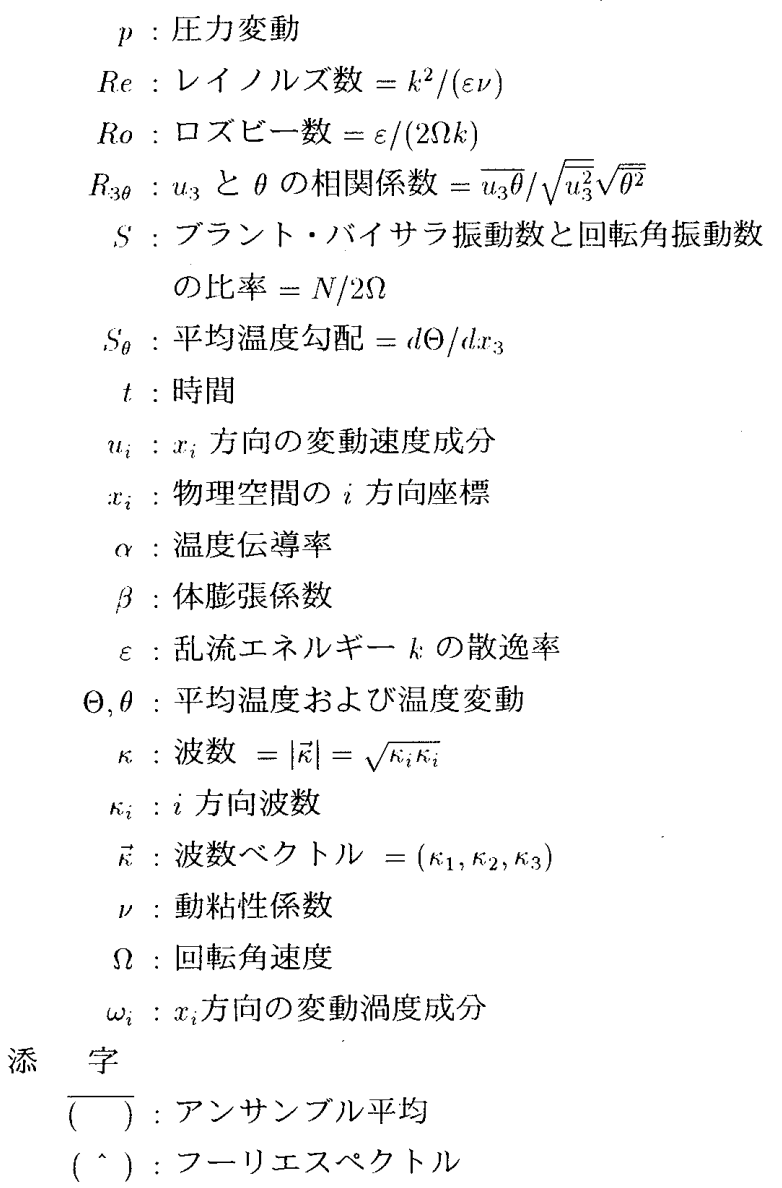

\section{3. 計算手法}

3.1 計算条件図1に座標系を示す.本研究では, 一様乱数により作り出した低レイノルズ数一様等方性乱 れの減衰過程を検討対象とする. 計算領域は, 辺長 $2 \pi$ の立方体であり，各断面に周期境界条件を課した。ま た，鉛直軸 $\left(x_{3}\right.$ 軸) を中心軸として系全体を $\Omega$ の角速度 で回転させた。さらに， $x_{3}$ 軸方向に一定の平均温度勾 配 $S_{\theta}$ と重力加速度 $g$ が重畳し, 流れ場は密度成層下に ある。本研究では， $g$ が $x_{3}$ 軸に平行下向きに作用する ため，S が正の場合には安定成層，また負の場合には 不安定成層となる。

数值的に解いた支配方程式は，ブジネスク近似(浮力 を考慮，コリオリ力及び遠心力に加わる密度変化は無

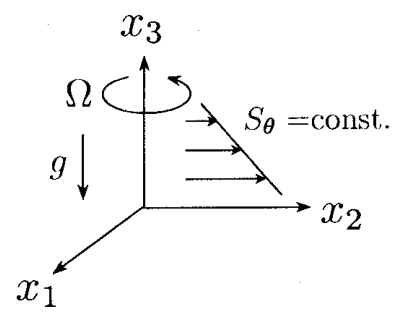

Fig.1 Flow geometry and coordinate system.
視)を仮定した非圧縮性ナビエ・ストークス方程式, 連 続の式およびエネルギ一方程式からなる。

計算条件を表 1 に示寸.ここで，記号 $\mathrm{N}, \mathrm{S}, \mathrm{U}$ はそれ ぞれ，中立成層，安定成層执よび不安定成層を示し， $\mathrm{R}$ は回転系であることを示す．また，表中のパラメ一夕 $S$ は,ブラント・バイサラ振動数と回転角振動数との比を 亦し，次のように定義した。

$$
S \equiv \frac{\sqrt{\left|g \beta S_{\theta}\right|}}{2 \Omega}
$$

安定, 不安定成層下の回転系流れ (Case SR1 SR3, Case UR $1 \sim \mathrm{UR} 6)$ については, $g \beta$ および $\Omega$ を変化させ, 浮 力の影響に比べ回転の影響が強い $S=0.05,0.1,0.2$ の 3 通りの流れ場について検討した。また，Case UR7 UR12については, $g \beta, \Omega$ は UR $1 \sim \mathrm{UR} 6$ と同じである が，格子点数を各方向に倍にした. 更に，初期速度場と して，回転軸方向に対して最も小さい波数 $\left(\kappa_{3}=0\right)$ に対 する速度スペクトルを，いずれの成分についても零とし た.これは, $x_{3}$ 方向の初期積分長さスケールを零とし たことに相当する.さらに，Case NR1，SR1，UR1, UR7 においては, Rapid Distortion Theory (RDT) による解析 も行った.

数值計算は，擬スペクトル法のアルゴリズムを基本 とし，支配方程式をフーリエ選点法により空間離散し た. 格子点数 $N_{g}$ は $32^{3}$ または $64^{3}$ である. 時間積分に は 2 次の Runge-Kutta 法を用いた。初期条件としては， 連続の式を満足する等方的な速度乱れを, 一様乱数を 用いて作成した。初期温度乱れについては, 全てのケ一 スにおいて零とした。

3.2 無次元パラメータ ブジネスク近似のナビエ・ ストークス方程式，連続の式およびエネルギ一方程式 を，適当な代表長さ $L$ ，速度スケール $U$ および代表温 度 $\Delta T\left(\equiv\left|d \Theta / d x_{3}\right| L\right)$ で無次元化すると，以下のように なる。

$$
\begin{aligned}
& \frac{\partial u_{i}}{\partial t}+u_{j} \frac{\partial u_{i}}{\partial x_{j}}=-\frac{\partial p}{\partial x_{i}}+\frac{1}{R e} \frac{\partial^{2} u_{i}}{\partial x_{j} \partial x_{j}} \\
& -\frac{1}{R o}\left(-u_{2} \delta_{i 1}+u_{1} \delta_{i 2}\right)+\frac{\theta}{B o} \delta_{i 3} . \\
& \frac{\partial u_{i}}{\partial x_{i}}=0 \\
& \frac{\partial \theta}{\partial t}+u_{j} \frac{\partial \theta}{\partial x_{j}}=-u_{3}+\frac{1}{\operatorname{RePr}} \frac{\partial^{2} \theta}{\partial x_{j} \partial x_{j}}
\end{aligned}
$$

ここで, Re $=U L / \nu, R o=U /(2 \Omega L), B o=U^{2} /(L g \beta \Delta T)$ であり，それぞれレイノルズ数，ロズビ一数，および 浮力パラメータと呼ばれ，対流項に対する粘性項，コ リオリ力項, 浮力項の比を表している.また，粘性項 とコリオリ力項の比は, $E k=\nu /\left(2 \Omega L^{2}\right)$ であり, エクマ ン数と呼ばれる。ここで，代表スケールに大スケール 
Table 1 Computational conditions

\begin{tabular}{|c|c|c|c|c|c|c|c|c|c|c|c|c|c|c|c|c|c|c|c|c|}
\hline Case & $\mathrm{N}$ & NR1 & NR2 & $\mathrm{S}$ & SR1 & SR2 & SR3 & $\mathrm{U}$ & UR1 & UR2 & UR3 & UR4 & UR5 & UR6 & UR7 & UR8 & UR9 & UR10 & UR11 & UR 12 \\
\hline$N_{g}$ & \multicolumn{14}{|c|}{$32^{3}$} & \multicolumn{6}{|c|}{$64^{3}$} \\
\hline$\nu$ & \multicolumn{14}{|c|}{0.0243} & \multicolumn{6}{|c|}{0.012} \\
\hline$P r$ & & .71 & 10 & \multicolumn{17}{|c|}{0.71} \\
\hline$S_{\theta}$ & \multicolumn{7}{|c|}{1} & \multicolumn{13}{|c|}{-1} \\
\hline$g \beta$ & 0 & 0 & 0 & 4 & 4 & 1 & 16 & 4 & 4 & 1 & 4 & 1 & 4 & 16 & 4 & 1 & 4 & 1 & 4 & 16 \\
\hline$\Omega$ & 0 & \multicolumn{2}{|c|}{10} & 0 & \multicolumn{3}{|c|}{10} & 0 & 10 & 5 & 20 & 10 & 5 & 10 & 10 & 5 & 20 & 10 & 5 & 10 \\
\hline$S$ & & & & & 0.1 & 0.05 & 0.2 & & \multicolumn{2}{|c|}{0.1} & \multicolumn{2}{|c|}{$\frac{1}{0.05}$} & \multicolumn{2}{|c|}{0.2} & \multicolumn{2}{|c|}{0.1} & \multicolumn{2}{|c|}{0.05} & \multicolumn{2}{|c|}{0.2} \\
\hline
\end{tabular}

渦 (エネルギー保有渦) を表す速度および長さスケール $\left(\sqrt{k}\right.$ および $\left.k^{3 / 2} / \varepsilon\right)$ を用いると, 各パラメーターはそれ ぞれ $R e=k^{2} /(\varepsilon \nu), R o=\varepsilon /(2 \Omega k), B o=\varepsilon /(\sqrt{k} g \beta \Delta T)$, $E k=\nu \varepsilon^{2} /\left(2 \Omega k^{3}\right)$ となる. 安定および中立成層では, $R e$ 数は計算時間全体に亘りほぼ 20 以下となっている. 不 安定成層下では, 格子点数が $32^{3}$ および $64^{3}$ の場合につ いて, Re 数はそれぞれ 100,200 程度まで増加する(こ の場合でも高波数部におけるエネルギースペクトルの 不自然な跳ね上がりは見られず，格子解像度は十分であ る).また，回転系において $R o$ 数， $E k$ 数は共に 0.1 以 下であり，回転軸に対して垂直な断面では，圧力勾配と コリオリカが釣り合い, 速度べクトルが等圧線に沿った いわゆる地衡的な流れ場となる.

\section{4. 計算結果および考察}

4 -1 中立および安定成層下の回転乱流 中立成層下 にある回転系 Case NR1 について， $x_{1}-x_{3}$ 平面での温度 変動 $\theta$ と速度べクトルの分布を図 2 に示す．回転の影 響により，温度乱れの分布が $x_{3}$ 軸方向 (回転軸方向) に 変化がなくなり，2 次元化しているのが見られる。

この回転系における温度乱れの 2 次元化のメカニズ ムについて，RDTを用いて検討する. 非線形項および 粘性項, 拡散項を省略することで次の解析解が得られ る.ただし, $\hat{u}_{j}(\vec{\kappa}, t)$ は時刻 $t$ での波数 $\vec{\kappa}$ における速度 成分 $u_{j}$ のスペクトルとする.また, 初期温度乱れは零 とした。

• $\kappa_{3} \neq 0$ の場合

$$
\begin{aligned}
\hat{u}_{1}(\vec{\kappa}, t)= & \hat{u}_{1}(\vec{\kappa}, 0) \cos f t \\
& +\left\{\gamma \hat{u}_{1}(\vec{\kappa}, 0)+\zeta \hat{u}_{2}(\vec{\kappa}, 0)\right\} \sin f t \\
\hat{u}_{2}(\vec{\kappa}, t)= & \hat{u}_{2}(\vec{\kappa}, 0) \cos f t \\
& -\left\{\eta \hat{u}_{1}(\vec{\kappa}, 0)+\gamma \hat{u}_{2}(\vec{\kappa}, 0)\right\} \sin f t \\
\hat{u}_{3}(\vec{\kappa}, t)= & \hat{u}_{3}(\vec{\kappa}, 0) \cos f t \\
+ & (1 / \kappa)\left\{\kappa_{2} \hat{u}_{1}(\vec{\kappa}, 0)-\kappa_{1} \hat{u}_{2}(\vec{\kappa}, 0)\right\} \sin f t \\
\hat{\theta}(\vec{\kappa}, t)= & \left(S_{\theta} / 2 \Omega \kappa_{3}\right)\left[\kappa_{2}\left\{\hat{u}_{1}(\vec{\kappa}, t)-\hat{u}_{1}(\vec{\kappa}, 0)\right\}\right. \\
& \left.-\kappa_{1}\left\{\hat{u}_{2}(\vec{\kappa}, t)-\hat{u}_{2}(\vec{\kappa}, 0)\right\}\right]
\end{aligned}
$$

ここで，

$$
f=2 \Omega \frac{\kappa_{3}}{\kappa}, \gamma=\frac{\kappa_{1} \kappa_{2}}{\kappa_{3} \kappa}, \zeta=\frac{\kappa^{2}-\kappa_{1}^{2}}{\kappa_{3} \kappa}, \eta=\frac{\kappa^{2}-\kappa_{2}^{2}}{\kappa_{3} \kappa}
$$

である。

• $\kappa_{3}=0$ の場合

$$
\left.\begin{array}{rl}
\hat{u}_{j}(\vec{\kappa}, t) & =\hat{u}_{j}(\vec{r}, 0) \\
\hat{\theta}(\vec{r}, t) & =-S_{\theta} \hat{u}_{3}(\vec{\kappa}, 0) t
\end{array}\right\}
$$

回転系での温度乱れは, 式 (6) から時間の増加と共に $\kappa_{3}=0$ の項が線形的に増大することが分かる。これに 対し, $\kappa_{3} \neq 0$ の項は有限の振幅で振動し, 時間と共に 増加できない $[$ 式 (5)]. この結果, $t$ が十分に大きくなる と, 温度乱れは $x_{3}$ 軸方向に一様になり 2 次元化する.

図 3(a), (b) に, 乱流熱流束 $\overline{u_{3} \theta}$ の時間変化を示す.こ こで, 図 $3(\mathrm{~b})$ については, 時間 $t$ をブラント・バイサ ラ振動数 $N\left(=\sqrt{g \beta S_{\theta}}\right)$ で無次元化した. 中立成層にお ける $\overline{u_{3} \theta}$ の増加は，回転系の方が非回転系に比べて明 らかに抑えられているのが分かる。これは，温度乱れ の鉛直方向への輸送が, 低波数 $\left(\kappa_{3}=0\right)$ の速度変動に よってのみ生じるためである。回転の影響による乱流熱 流束の抑制は, 中立成層のみならず安定成層と不安定 成層の場合にも生じることが分かる.また，図 3(b) か

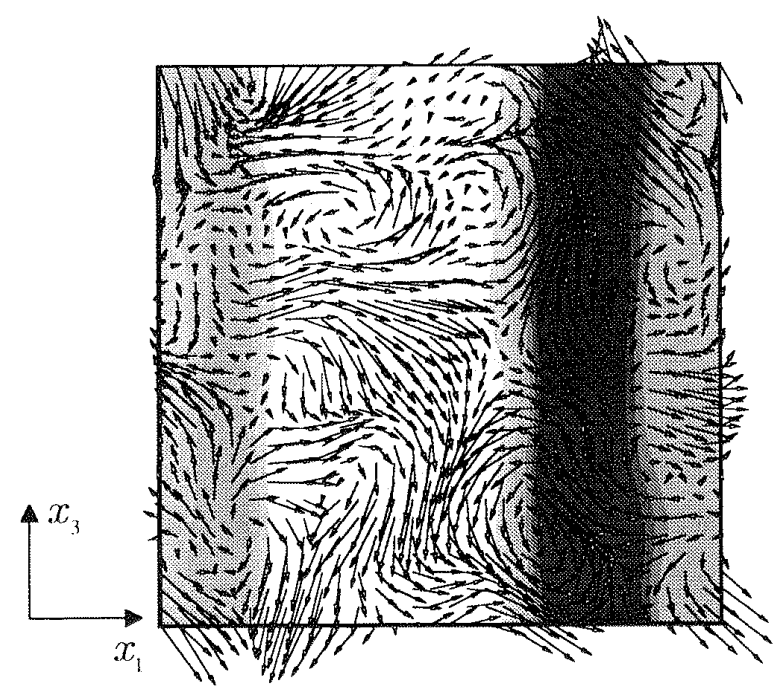

Fig.2 Distributions of temperature fluctuation and velocity vectors in the $x_{1}-x_{3}$ plane at $t=2.0$ (Case NR1) : Black to white, $\theta=-0.5$ to 0.5 . 

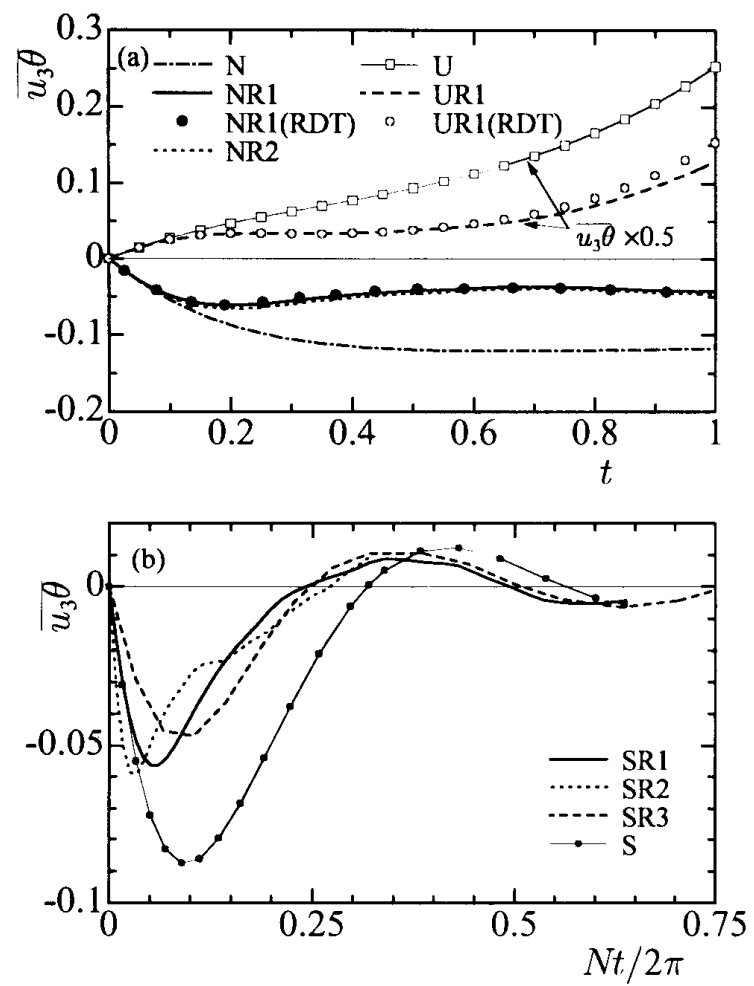

Fig.3 Time evolution of $\overline{u_{3} \theta}$. (a) Cases N, NR1, NR2, U, UR1; (b) Cases S, SR1-3.

ら，安定成層下における回転系では， $\overline{u_{3} \theta}$ の振動周期が $N t / 2 \pi=1 / 2$ となるのに対して, 非回転系ではそれより も周期が長くなっている.

ここで，安定成層下における鉛直方向速度 $u_{3}$ と温度 変動 $\theta$ について, 中立成層の場合と同様, 非線形項およ び拡散項を無視することにより次の解析解が得られる。

$$
\left.\begin{array}{rl}
\hat{u}_{3}(\vec{\kappa}, t)= & \hat{u}_{3}(\vec{\kappa}, 0) \cos f t \\
+\left(2 \Omega \kappa_{3} / f \kappa^{2}\right)\left\{\kappa_{2} \hat{u}_{1}(\vec{\kappa}, 0)-\kappa_{1} \hat{u}_{2}(\vec{r}, 0)\right\} \sin f t \\
\hat{\theta}(\vec{\kappa}, t)=-S_{\theta}\left\{\hat{u}_{3}(\vec{\kappa}, 0) / f\right\} \sin f t \\
+S_{\theta}\left(2 \Omega \kappa_{3} / f^{2} \kappa^{2}\right) \\
\quad\left\{\kappa_{2} \hat{u}_{1}(\vec{\kappa}, 0)-\kappa_{1} \hat{u}_{2}(\vec{\kappa}, 0)\right\}(\cos f t-1)
\end{array}\right\}
$$

ここで $f$ は角振動数であり，以下のようになる。

$$
f^{2}=\frac{N^{2}\left(\kappa_{1}^{2}+\kappa_{2}^{2}\right)+4 \Omega^{2} \kappa_{3}^{2}}{\kappa_{1}^{2}+\kappa_{2}^{2}+\kappa_{3}^{2}}
$$

回転系では， $\kappa_{3}=0$ に対応する温度変動 $\theta$ が大きな值を 持ち, 速度変動 $u_{3}$ と高い相関を持つ. 従って, この波 数の速度変動および温度変動が振動を起こしたために, 速度変動と温度変動は式 $(7),(8)$ よりそれぞれ $f=N$ の角振動数で振動し，一方これらの相関は，図 $3($ (b) に 示したように $2 f=2 N$ の角振動数で振動するものと考 えられる。

4.2 不安定成層下の回転乱流図 4 に, 不安定成層 下の回転系における $x_{1}-x_{3}$ 平面での温度変動 $\theta$ と速度 ベクトルの分布を示す．この図から，中立成層下にある

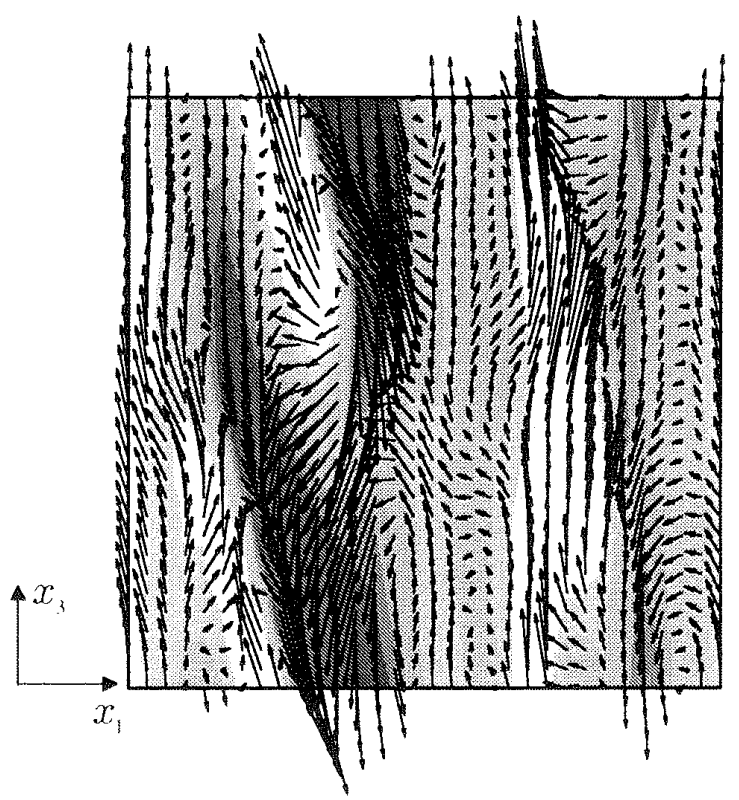

Fig.4 Distributions of temperature fluctuation and velocity vectors in the $x_{1}-x_{3}$ plane at $t=2.0$ (Case UR1) : Black to white, $\theta=-1.8$ to 1.8 .

回転系の場合と同様に，温度変動が回転軸方向に2次 元化しているのが見られる.さらに，不安走成層下で は，温度変動が正の領域では速度べクトルが上向き，負 の領域ならば下向きに対応している．また，この上昇， 下降運動は水平方向にねじられており，回転運動を伴う ものであることが分かる。

温度乱れおよび速度変動の 2 次元化は, 初期積分長さ スケールの有無によらず，いずれの DNSにおいても生 じた。初期積分長さスケールが零でない場合には, RDT によっても 2 次元化は生じるが, 螺旋状の速度べクト ルの分布は見られなかった。また, 積分長さスケールを 零とした初期速度場を用いた場合，RDTによる解析で は, 温度乱れは 2 次元化せず, 乱流熱流束の増加も見 られなかった。

そこで次に, 初期条件における積分長さスケールの有 無が RDT の解に大きな影響を与える理由を考察する。 式 $(8)$ に示した固有振動数が, 安定成層下 $\left(S_{\theta}>0\right)$ では 常に $f^{2}>0$ となるのに対して, 不安定成層下 $\left(S_{\theta}<0\right)$ では $N^{2}<0$ のため, 波数 $\kappa_{i}$ の值によって $f^{2}>0$ また は $f^{2}<0$ となる. $f^{2}<0$ の場合には, 式 (7)の解析解 は, 周期関数ではなく双曲線関数となり，この波数にお ける $\hat{u}_{3}, \hat{\theta}$ は，時間と共に増加する. $f^{2}<0$ となり, 乱 れが指数関数的に增大するための各波数についての条 件は, 以下の式 (9) で示される.

$$
S^{2}>\frac{\kappa_{3}^{2}}{\kappa_{1}^{2}+\kappa_{2}^{2}}
$$


(a)

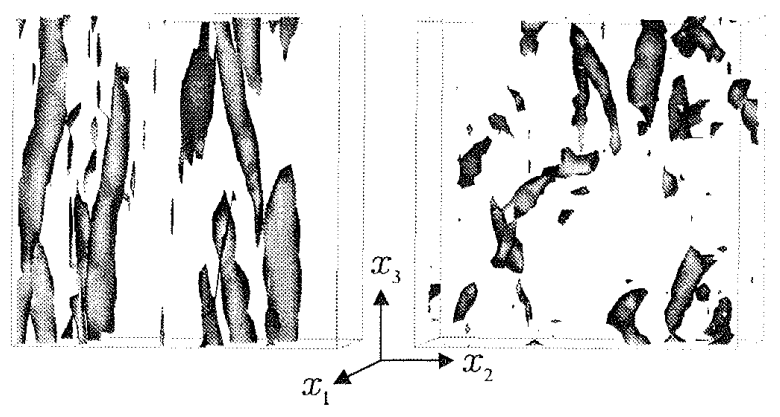

Fig.5 Iso-surfaces of $\omega_{3}$. (a) Case UR $1, \omega_{3}=2.0$ at $t=$ $2.0 ;$ (b) Case U, $\omega_{3}=2.0$ at $t=2.0$.

回転の影響の強い流れ場では $S\left(=\sqrt{\left|\boldsymbol{g} \beta S_{\theta}\right|} / 2 \Omega\right)$ が小さく なるため, 式(9)より, $\overline{u_{3}^{2}}$ および $\overline{\theta^{2}}$ の増加は主に $\kappa_{3}=0$ のエネルギーに依存することが分かる．ただし，初期速 度場の積分長さスケールが零, すなわち $\kappa_{3}=0$ に対応 する $u_{3}$ のスペクトルが零の場合には，RDTによる解析 では $\overline{u_{3}^{2}}, \overline{\theta^{2}}$ は增加できず, また温度乱れの 2 次元化も 生じない。

次に，Case UR1 での $\omega_{3}$ の等値面を図 5(a) に示す。 また参考のため，不安定成層下での非回転系 Case U に おける $\omega_{3}$ の等值面を図 5(b) に示す. 不安定成層下の回 転系流れでは，回転軸 $x_{3}$ を渦軸とする渦管が $x_{3}$ 方向 に長く伸びており，回転のない場合とは際だった違いが 見られる。しかし，非線形効果を無視する RDTにより 回転系の不安定成層流を計算した場合には，初期積分 スケールの有無によらず，図 5(a)に示した渦管は確認 できなかった。

4.2.1 渦管の生成機構上述のように，不安定成層 下にある回転流れでは渦管が生成される。そこで，こ の渦管の生成メカニズムについて検討する.Case UR1, Case Uについての圧力変動 $p$ と $\omega_{3}$ の結合確率密度分布 を，それぞれ図 6(a)，(b)に示す.図５で示した洞構造 ( $\left|\omega_{3}\right|$ が大きい領域) は，Case U では主に低圧部 $(p<0)$ に対応しているのに対し，Case UR1では低圧部には正 の渦度，高圧部には負の渦度が対応しているのが見ら れる.これは，長く伸びた渦管が，圧力勾配とコリオリ 力が釣り合った地衡流平衡のもとで生成されているこ とを示すものである。

一方, $\overline{\omega_{3}^{2}}$ の輸送方程式は次の式 (10) で与えられる.

$$
\begin{aligned}
\frac{\partial \overline{\omega_{3}^{2}}}{\partial t}=\underbrace{\overline{2 \omega_{1} \omega_{3} \frac{\partial u_{3}}{\partial x_{1}}}}_{V_{1 \omega}}+\underbrace{\overline{2 \omega_{2} \omega_{3} \frac{\partial u_{3}}{\partial x_{2}}}}_{V_{2 \omega}}+\underbrace{\overline{2 \omega_{3} \omega_{3} \frac{\partial u_{3}}{\partial x_{3}}}}_{V_{3 \omega}} \\
+\underbrace{4 \Omega \omega_{3} \frac{\partial u_{3}}{\partial x_{3}}}_{V_{L \omega}}-\underbrace{2 \nu \frac{\partial \omega_{3}}{\partial x_{j}} \frac{\partial \omega_{3}}{\partial x_{j}}}_{D_{\omega}} \ldots \ldots .
\end{aligned}
$$

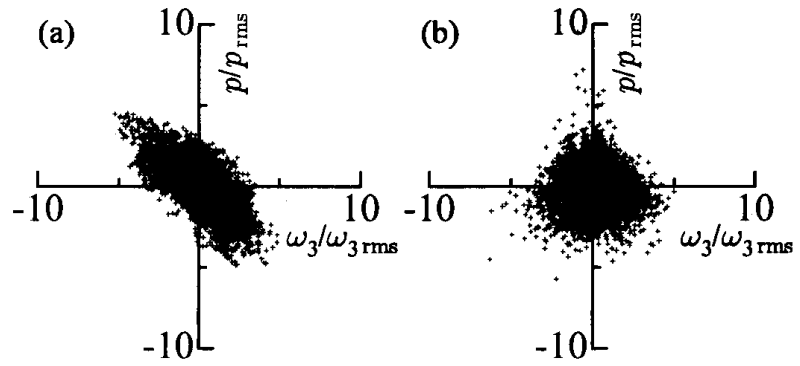

Fig.6 Joint p.d.f. between pressure $p$ and vertical vorticity $\omega_{3}$. (a) Case UR1 at $t=2.0$; (b) Case U at $t=2.0$.

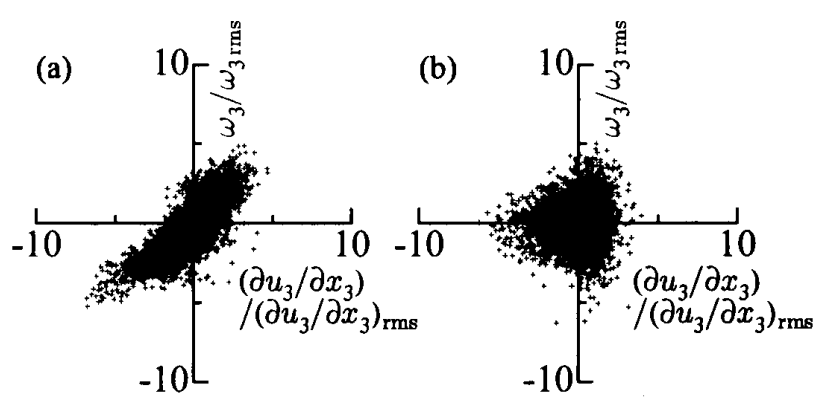

Fig.7 Joint p.d.f. between vertical vorticity $\omega_{3}$ and $\partial u_{3} / \partial x_{3}$. (a) Case UR1 at $t=2.0$; (b) Case U at $t=2.0$.

式(10)の $V_{3 \omega}$ および $V_{L \omega}$ は，それそれ非線形，線形の渦 伸縮による生成項 (または消滅項) である.そこで，こ れらの項の効果を見るために，図7(a)，(b) に $\omega_{3}$ と歪 み速度 $\partial u_{3} / \partial x_{3}$ の結合確率密度分布を示した。図 7(a) から，Case UR1 では，正および負の $\omega_{3}$ はそれそれ正， 負の $\partial u_{3} / \partial x_{3}$ に対応しており，主に線形渦伸縮を示す $V_{L \omega}$ による生成が $\overline{\omega_{3}^{2}}$ の增加に貢献していると見なすこ とができる．従って，Case UR1で見られた回転軸方向 に長く伸びた渦管は，式 (10) 中の線形の渦伸縮によっ て生成されることが分かる。これに対し，Case Uでは， 図 7(b) から，正負の大きな渦度は主に正の $\partial u_{3} / \partial x_{3}$ に 対応しており， $\overline{\omega_{3}^{2}}$ の增加は，主に非線形渦伸縮 $V_{3 \omega} に$ よる生成であると考えられる。

次に， $g \beta$ と $\Omega$ を変化させ，パラメー夕の影響による 渦構造の変化を検討する. 図 8 に, Case UR1 〜 UR6 に おける $\omega_{3}$ の時間変化を示す．ここで，横軸は $\Omega$ で無次 元化している. パラメータ $S\left(=\sqrt{\left|g \beta S_{\theta}\right|} / 2 \Omega\right)$ によって $\omega_{3}$ の時間変化が整理できることが分かる．また，図 9 に $u_{3}$ と $\theta$ の相関係数 $R_{3 \theta}$ の時間変化を示す. $R_{3 \theta}$ は， 減衰初期では回転の影響により $S$ によず一定の勾配 で減少し，その後 $S$ によって異なる時刻で再び増加す る. 相関係数の時間変化についても，Sによって整理で きる.そして，図 8 と図 9 を比較することにより， $\omega_{3}$ 


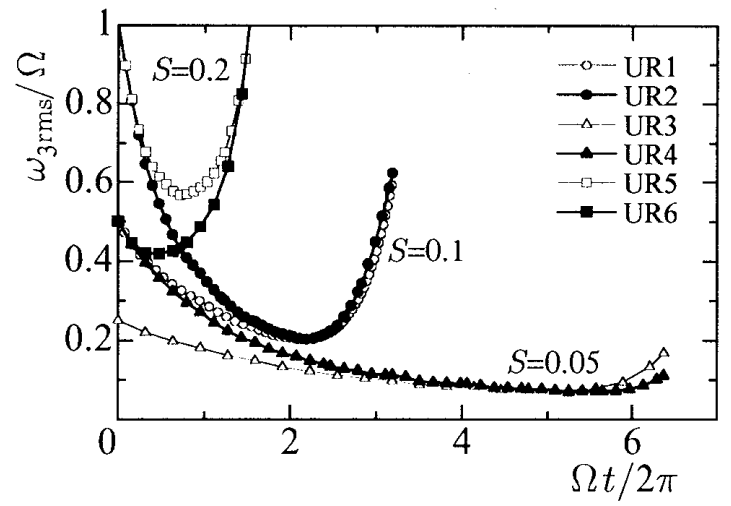

Fig.8 Time evolution of $\omega_{3}$ in Cases IR1-6.

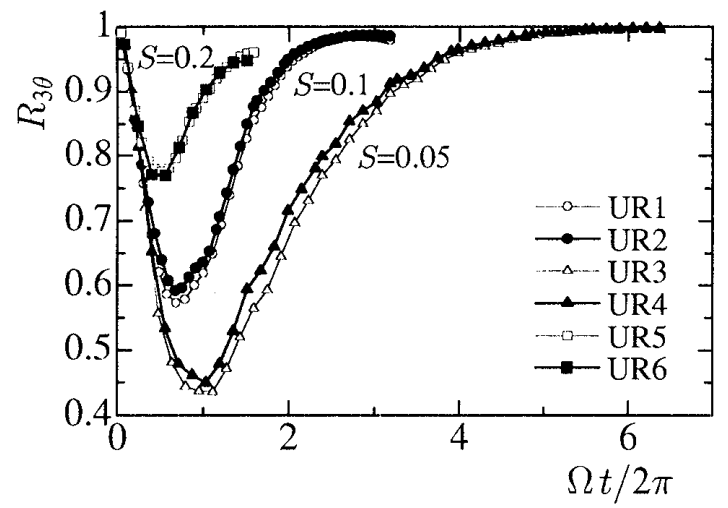

Fig.9 Time evolution of $R_{30}$ in Cases UR1-6.

の增加し始める時間は, 相関係数が増加し $R_{3 \theta} \simeq 1$ と なる時閶とほぼ一致していることが分かる。すなわち， 速度場と温度場が 2 次元化した後に渦が発生する.さ らに，らが小さいほど渦の発生が遅れることも分かる. Case UR7〜UR12 についても, 図10，11に示すように， $\omega_{3}$ および $R_{3 \theta}$ の特間変化は $S$ によってよく整理される. 計算条件で示したように, Case UR7 UR.12の初期速 度場 $\hat{u}_{j}(\vec{k}, 0)$ は， $\kappa_{3}=0$ に対するエネルギ一を零として いる.このため, Case UR1〜UR6の場合に比心゙，相関 係数および渦度が增加するまでに㭙間がかかる。

典型的な润構造を見るために図 $12(\mathrm{a}),(\mathrm{b})$ に, Case UR7，UR10についてそれぞれ $\omega_{3 \mathrm{rms}}$ が増加した時刻 $\Omega t / 2 \pi=3.98, \Omega t / 2 \pi=8.75$ での $\omega_{3}$ の等值面を示した。 (ase UR10 では， Gase UR7 と比較して，相対的に渦構 造が回転軸方向に長く伸びている．また，大スケールの 構造のみ確認でき，小スケ一ルの構造は消失している。 当然, 速度場と温度場の瞬時構造もお互いに異なって いるはずである。上述の時刻での $r_{2}-r_{3}$ 平面における温 度乱れと速度べクトルの分布を図 13(a)，(b)に示した。 Case UR10では，速度および温度乱れの分布が，はっき りと2次元化しているのに対し, Case UR7では, どち らも水平方向に大きな変動を持っている.これは， $S$ が 小さい程, 回転の影響により一層小スケールの速度変

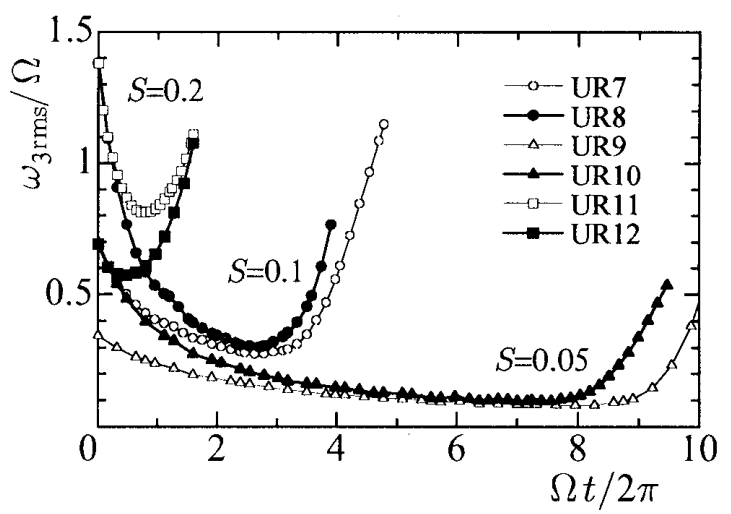

Fig.10 Time evolution of $\omega_{3}$ in Cases UR7-12.

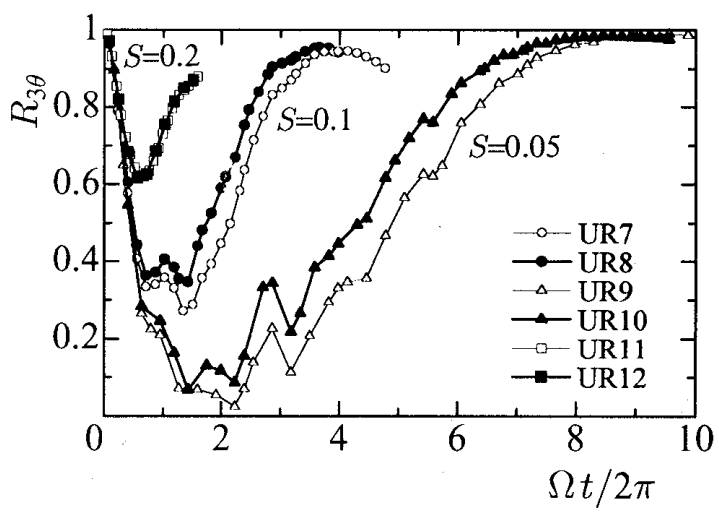

Fig.11 Time evolution of $R_{3 \theta}$ in Cases UR7-12.

動がより減衰した後に渦が発生 ( $\omega_{3 \mathrm{rms}}$ が増加) すること と対応する構造である。

$4 \cdot 2 \cdot 2$ 非線形効果最後に, 渦管の生成過程におけ る非線形効果について以下に検討する。まず，レイノ ルズ応力の対角成分の時間変化を図 14 に示した。初期 減衰後，回転流の Case UR1 では,レイノルズ応力の水 平方向成分 $\overline{u_{1}^{2}}, \overline{u_{2}^{2}}$ が $t=1.7$ 付近から増大するのに対し， 回転の影響のない Case U では，より早い $t=0.8$ 付近か ら増加している。レイノルズ応力の垂直方向成分 $\overline{u_{3}^{2}}$ に ついても，回転の影響により増加の開始が遅れている。 また，Case UR1 において RDT による計算を行うと， $\overline{u_{3}^{2}}$ の時關変化は DNS の結果とほぼ一致するのに対し，水 平方向成分 $\overline{u_{1}^{2}}, \overline{u_{2}^{2}}$ の増加は得られない。このことから， $\overline{u_{3}^{2}}$ の増加は主に線形作用であるのに対して，鉛直方向 に軸を持つ渦に関係する $\overline{u_{1}^{2}}, \overline{u_{2}^{2}}$ の增加は, 非線形作用 によると結論づけられる。この現象を別の観点から調 べるために， $\left(\partial u_{3} / \partial x_{3}\right)_{\mathrm{rms}}$ の時間変化を図 15 に示した。 Case UR1 では， $\left(\partial u_{3} / \partial x_{3}\right)_{\mathrm{rms}}$ が $t \simeq 1.7$ 付近から急激に 増加するのに対し, Case Uでは, $t \simeq 0.8$ から徐々に増 加している.図 14 と図 15 とを比べると, $\overline{u_{1}^{2}}, \overline{u_{2}^{2}}$ の増加 と $\partial u_{3} / \partial x_{3}$ の增加の開始が一致していることが分かる. 従って，水平方向の速度㧍よび鉛直方向渦度 $\omega_{3}$ の增加 は，回転軸方向の渦の伸縮に関係していることが改め 
(a)

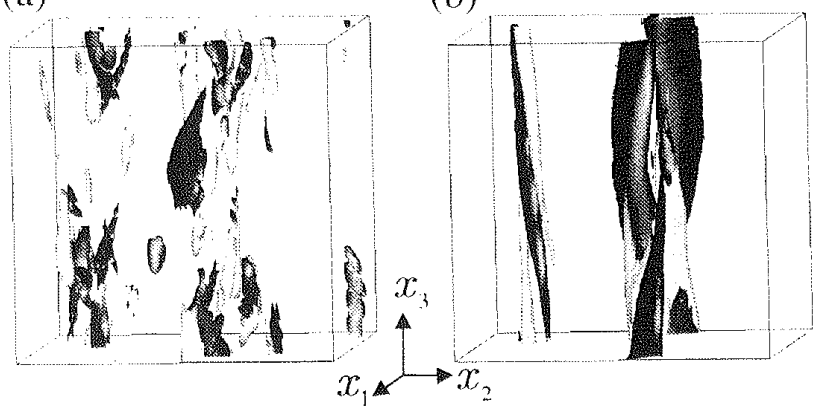

Fig.12 Iso-surfaces of $\omega_{3}$.

(a) Case UR7, white, $\omega_{3} / \omega_{3 \mathrm{rms}}=2.5 ;$ Black, $\omega_{3} / \omega_{3 \mathrm{rms}}=-2.5$ at $\Omega t .2 \pi=3.98$; (b) Case UR10, white, $\omega_{3} / \omega_{3 \mathrm{rms}}=$ 2.5; Black, $\omega_{3} / \omega_{3 \mathrm{rms}}=-2.5$ at $\Omega t / 2 \pi=8.75$. (a)

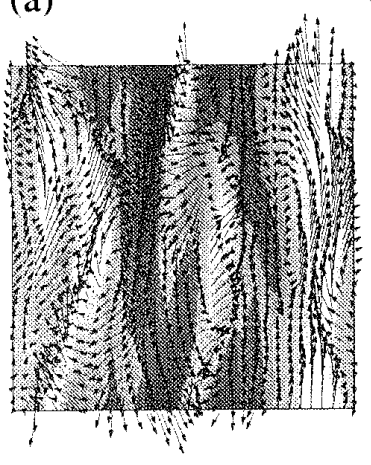

(b)

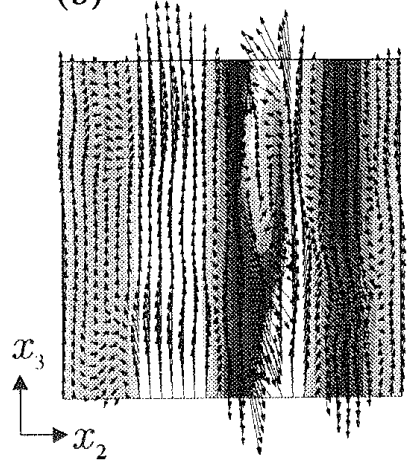

Fig.13 Distributions of temperature fluctuation and velocity vectors in the $x_{2}-x_{3}$ plane. (a)Case UR7, Black to white, $\theta=-1.0$ to 1.0 at $\Omega t / 2 \pi=3.98$; (b)Case UR10, Black to white, $\theta=-2.0$ to 2.0 at $\Omega t / 2 \pi=8.75$.

て確認できる．図15 から明らかなように，RDT では， $\left(\partial u_{3} / \partial x_{3}\right)_{\mathrm{rms}}$ の增加は得られない.

以上のことから，回転軸方向に長く伸びた渦管の生 成は, 歪み速度 $\partial u_{3} / \partial x_{3}$ に関係する線形の渦伸縮 [ 式 (10) の $\left.V_{L w}\right]$ によるが, $\overline{\left(\partial u_{3} / \partial x_{3}\right)^{2}}$ そのものの増加には， 非線形作用によるエネルギ一輸送を必要とすることが わかる．式(8) に示されるように，RDTによる解析で は, $\overline{u_{3}^{2}}$ のスペクトルが増加する波数は $f^{2}<0$ となる領 域 [式 (9)] で表され， $\partial u_{3} / \partial x_{3}$ に貢献する $\kappa_{3}$ が大きい波 数のエネルギーは振動し， $\overline{\left(\partial u_{3} / \partial x_{3}\right)^{2}}$ は増加できないと 考えられる。

このような不安定成層下の回転流の非線形作用を, 波 数空間で調べてみる.図 16 に，図 12 ，図 13 で示した 時刻での $\overline{u_{3}^{2}}$ の 3 次元エネルギースペクトル $E_{33}(\kappa)$ を示 す.ここで，図中の $E_{33}^{-}(\kappa)$ は， $E_{33}(\kappa)$ の内 $f^{2}<0$ を満 たす波数のエネルギースペクトルであり，線形効果によ

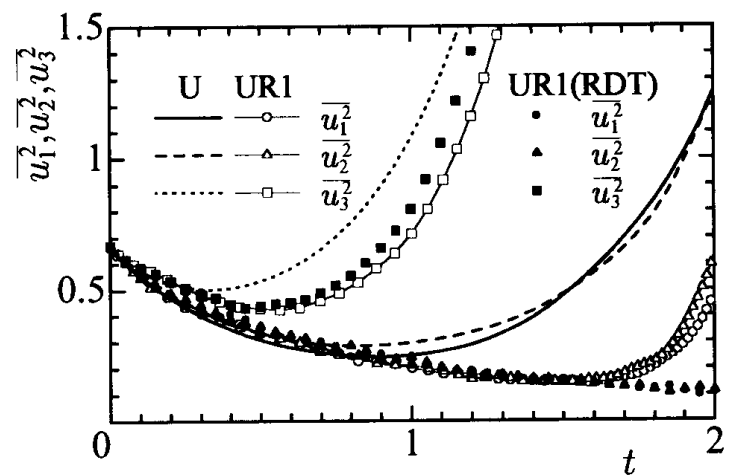

Fig.14 Time evolution of Reynolds stresses in Cases U and UR1.

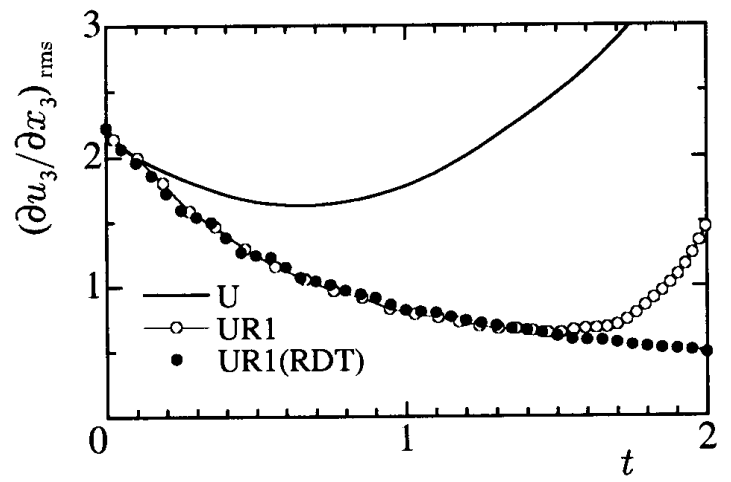

Fig.15 Time evolution of the r.m.s. value of strain rate $\partial u_{3} / \partial x_{3}$ in Cases U and UR1.

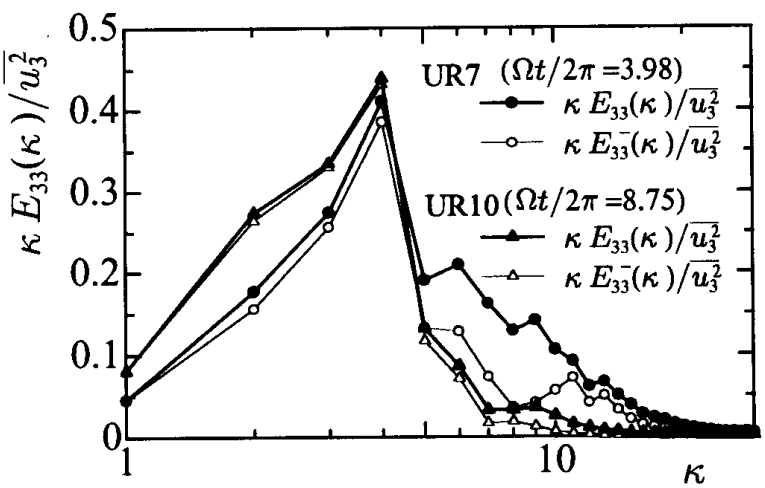

Fig.16 Three-dimensional energy spectrum of $\overline{u_{3}^{2}}$ in Cases UR7 and UR10.

り得られるエネルギ一を示す.この図から， $\overline{u_{3}^{2}}$ のエネル ギ一は, Case UR7, UR10 共に $\kappa=4$ より大きい波数で 急激に減衰している.特に Case UR10では高波数部で の減衰が大きい. そして， $\kappa=1 \sim 4$ 付近のエネルギー は $f^{2}<0$ の領域に支配されているのに対し， $\kappa=6 \sim 10$ 付近では, 非線形効果を示す $f^{2}>0$ に対応するエネル ギ一が増大している．なお， $f^{2}<0$ に対応するエネル ギ一は，同時に $\kappa_{3}=0$ を満たしている [ 図省略, 式 (9) 参照]. 


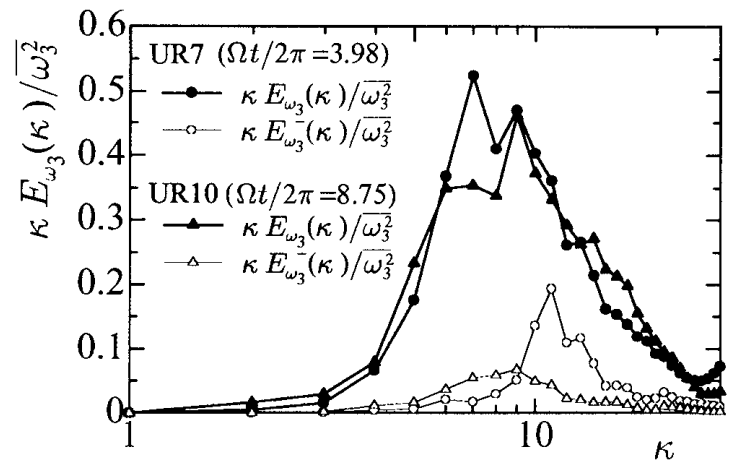

Fig.17 Three-dimensional energy spectrum of $\overline{\omega_{3}^{2}}$ in Cases UR7 and URI0.

一方, $\overline{\omega_{3}^{2}}$ の3 次元エネルギースペクトル $E_{\omega_{3}}(\kappa)$ は, 図 17 のようになっている。時刻は図16 と同じである。 $\overline{\omega_{3}^{2}}$ のスペクトルは, 主に上述の $f^{2}>0$ の領域に相当す る $\kappa=6 \sim 10$ の波数帯にある.これは, 鉛直方向渦度 $\omega_{3}$ の生成が， $f^{2}>0$ の領域にある鉛直方向速度変動 $u_{3}$ と関係することを裹づけるものである.

このような特徴的な現象を, 次式の $\overline{u_{3}^{2}}$ に関するスぺ クトル輸送方程式から最後に考察する.

$$
\begin{aligned}
\frac{\partial \hat{u}_{3} \hat{u}_{3}^{*}}{\partial t} & =\underbrace{\left(-i \kappa_{j} \widehat{u}_{3} u_{j} \hat{u}_{3}^{*}-i \kappa_{j} \widehat{u}_{3} \hat{u}_{j}^{*} \hat{u}_{3}\right)}_{T_{33}}-\underbrace{2 \nu \kappa^{2} \hat{u}_{3} \hat{u}_{3}^{*}}_{\hat{\varepsilon}_{33}} \\
& +\underbrace{\left(-i \kappa_{3} \hat{p} \hat{u}_{3}^{*}-i \kappa_{3} \hat{p}^{*} \hat{u}_{3}\right)}_{\hat{\phi}_{33}}+\underbrace{\left(g \beta \hat{\theta} \hat{u}_{3}^{*}+g \beta \hat{\theta}^{*} \hat{u}_{3}\right)}_{\hat{F}_{33}}
\end{aligned}
$$

式(11)において， $T_{33}$ は伝達関数， $\widehat{\varepsilon}_{33}$ は散逸， $\widehat{\phi}_{33}$ は圧 力歪み相関, $\hat{F}_{33}$ は浮力による生成または消滅を表して いる. 図 18 に式(11)の各項の值を示した。図より，低 波数域では浮力による生成が $\overline{u_{3}^{2}}$ のゲインとして大きく 寄与するのに対して, 罒 16 に示される $f^{2}>0$ に対応す るエネルギーが增大する領域は, 伝達関数 (非線形作用 を表す)によるゲインが生じる領域と対応することが分 かる. 従って，伝達関数によるエネルギ一の順カスケー ド輸送が， $f^{2}>0$ の領域での $\overline{u_{3}^{2}}$ のエネルギ一を増加さ せるものと考えられる。

\section{5. 結論}

密度成層下にある回転流に生じる大規模構造と熱輸 送特性について，一様等方性乱れを初期值とした直接 数值シミュレーションおよびラピッドディストーション 理論による解析を行うことにより，以下の結論を得た。

（1）低レイノルズ数の回転系流れでは，熱は回転軸方 向にのみ輸送されるため, 温度変動の瞬時分布は軸方 向に一様になり 2 次元化する.

(2) 安定成層下の回転系流れでは, $\kappa_{3}=0$ に対応する 速度変動と温度変動が大きな値を持ち, これらはブラ ント・バイサラ振動数で振動する.
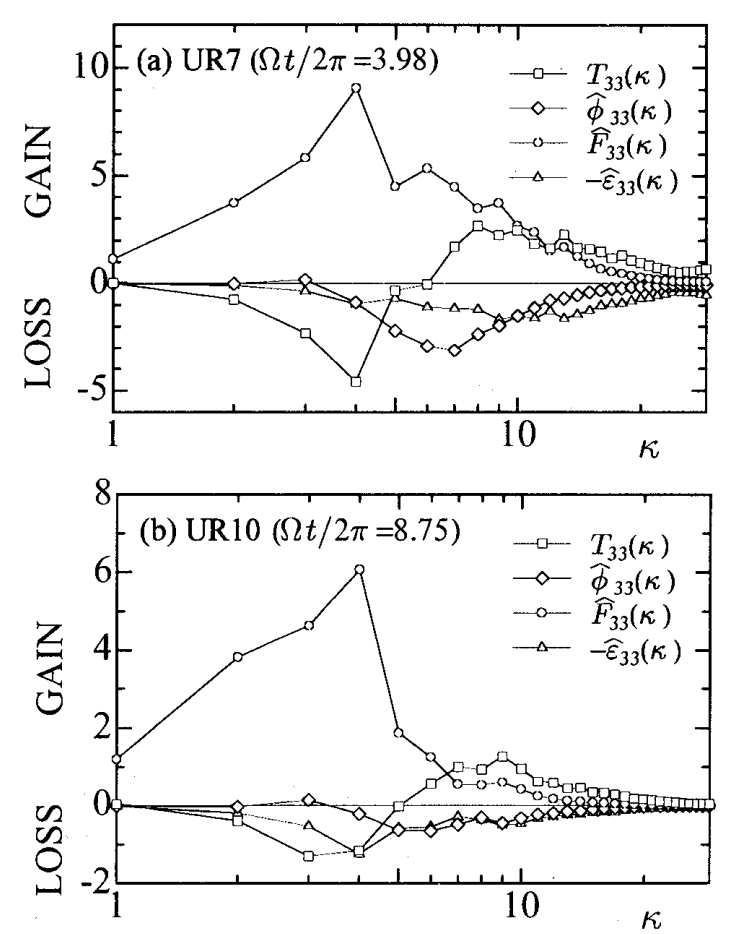

Fig.18 Transport terms of energy spectrum of $\overline{u_{3}^{2}}$. (a) Case UR7; (b) Case UR10.

(3) 不安定成層下の回転系流れでは，回転軸を渦軸と する渦管が長く伸びる。この渦管の生成は，回転角速 度 $\Omega$ と鉛直方向歪み速度 $\partial u_{3} / \partial x_{3}$ による線形渦伸縮に よる.しかし， $\partial u_{3} / \partial x_{3}$ が振動せずに増加するには，非 線形作用を必要とする。すなわち，伝達関数による低波 数から高波数へのエネルギー輸送により $\partial u_{3} / \partial x_{3}$ が增 大することが不可欠である。

本研究は, 文部省科学研究費補助金基盤研究 $(B)(N 0)$ 10450085)の援助を受けた。ここに記して謝意を表する.

\section{文献}

(1) Nakagawa, Y. and Frenzen, P., Tells 7, (1955), $1-21$.

(2) Rossby, H. T., J. Fluids Mech. 36, (1969), $309-335$.

(3) Busse, F. H. and Heikes, K. E., Science 208, (1980), 173 -174 .

(4) Fernando, H. J. S., Chen, R. and Boyer, D. L., J. Fluids Mech. 228, (1991), 513- 547.

(5) Speer, K. G., Geophys. Res. Lett. 16, (1989), $461-464$.

(6) Julien, K., Legg, S., McWilliams, J. and Werne, J., Physical Review E 53, (1996), 5557R - 5560R.

(7) Julien, K., Legg, S., McWilliams, J. and Werne, J., J. Fluids Mech. 322, (1996), 243- 273.

(8) Raach, S. and Etling, D., Beitr, Phys, Atmosph. 64, (1991), $185-199$.

(9) McWilliams, J. C., J. Fluids Mech. 198, (1990), $199-230$.

(10) Lesieur, M., Turbulence in Fluids, 2nd ed., Kluwer Academic Publishers, The Netherlands, (1990).

(11) McWilliams, J. C., Weiss, J. B. and Yavneh, I., Science 264, (1994), $410-413$. 